\title{
A LEITURA NAS SÉRIES INICIAIS DO ENSINO FUNDAMENTAL: DIFICULDADES, AVANÇOS, ENTRAVES E PERSPECTIVAS
}

\section{ARTIGO DE REVISÃO}

CHAVES, Patrícia Aparecida Morais Alves ${ }^{1}$

CHAVES, Patrícia Aparecida Morais Alves. A leitura nas séries iniciais do ensino fundamental: dificuldades, avanços, entraves e perspectivas. Revista Científica Multidisciplinar Núcleo do Conhecimento. Ano 04, Ed. 11, Vol. 05, pp. 31-46. Novembro de 2019. ISSN: 2448-0959, Link de acesso: https://www.nucleodoconhecimento.com.br/educacao/leitura-nas-seriesiniciais

\section{RESUMO}

O presente artigo tem por objetivo fazer uma retrospectiva histórica da prática de leitura nas séries iniciais e analisar como a instituição escolar, docentes e família têm contribuído atualmente para a aquisição e desenvolvimento da leitura nessas séries. O trabalho consta de análise teórica baseada em autores como Solé (1998), PCN's de Língua Portuguesa (1997), Martins (2007), Freire (1993), Maia (2007), Kleiman (1993), Geraldi (1984 e 1996), dentre outros. Sabe-se que a leitura é uma das principais atividades da instituição escolar e precisa ser trabalhada com dedicação, pois, a aquisição dela, é base para o desenvolvimento cognitivo e para o processo de ensino e aprendizagem do aluno. Portanto, pretende-se com a elaboração desse artigo, estimular as escolas, docente e famílias de uma maneira geral a refletirem juntos sobre o seu papel na formação de leitores, e levá-los a questionarem sobre as

1 Especialização em Aprendizagem e Autoria na Educação Infantil e Ensino Fundamental na Universidade Estadual do Maranhão - UEMA; Especialização em Educação em Direitos Humanos na Universidade Federal do Maranhão - UFMA; Bacharel em Administração de Empresas na Universidade Federal do Maranhão UFMA e Licenciatura em Pedagogia na Universidade Federal do Tocantins - UFT. 
causas que levam às dificuldades de leitura e consequentemente propor estratégias para superá-las. Em suma, a metodologia utilizada para o alcance do objetivo foi a pesquisa bibliográfica. Os resultados alcançados evidenciam que atitudes simples muitas vezes são as mais importantes e exercem papel fundamental na busca pelo conhecimento.

Palavras-chave: Leitura, dificuldades, avanços, séries iniciais.

\section{INTRODUÇÃO}

O artigo trata-se de pesquisa bibliográfica sobre as dificuldades de leitura nas séries iniciais do Ensino Fundamental, de grande relevância, pois amplia uma discussão sobre os problemas presentes nas escolas que precisam ser solucionados para que sejam formados leitores intelectualmente independentes na atualidade.

A pesquisa surgiu da necessidade de se analisar e verificar como se realiza a leitura nas escolas e sociedade, para isto, buscou-se responder os seguintes questionamentos: Quais são as causas das dificuldades de leitura nas séries iniciais? Como a instituição escolar, docentes e famílias têm contribuído para o processo de aquisição e desenvolvimento da leitura nas séries iniciais do Ensino Fundamental? Quais são os avanços, entraves e perspectivas em relação à superação das dificuldades de leituras nessas séries?

A mesma, aborda as responsabilidades que escolas, docentes e famílias têm juntos na formação de leitores, na tentativa de se chegar a conclusões satisfatórias sobre as causas das problemáticas levantadas no que se refere às dificuldades de leituras nas séries iniciais do Ensino Fundamental.

Sabe-se que a leitura é uma das principais atividades da instituição escolar e precisa ser trabalhada com dedicação, pois, a aquisição da mesma, é base para o desenvolvimento cognitivo e para o processo de ensino e aprendizagem do aluno. Kleiman (1993 apud Maia, 2007, p.15), diz que "grande número de professores não são leitores, e tem, no entanto, que ensinar a ler e a gostar de ler". 
Tem-se por objetivo geral fazer uma retrospectiva histórica da prática de leitura nas séries iniciais no Brasil desde o Período colonial até os dias atuais, analisando como se dá o processo de aprendizagem da leitura e como a mesma é trabalhada no contexto escolar e familiar, para que sejam discutidos as causas das dificuldades apresentadas na leitura e a importância do auxílio dos docentes e da família para aquisição da competência leitora dos alunos, que é a base da desenvoltura intelectual, cultural, política e histórica e que favorece o desenvolvimento do senso crítico.

A metodologia utilizada na pesquisa consta de análise teórica baseada em autores como Solé (1998), PCN's de Língua Portuguesa (1997), Martins (1994), Freire (1993), Maia (2007), Kleiman (1993), Geraldi (1984 e 1996), dentre outros. Em suma, a metodologia utilizada para o alcance do objetivo foi a pesquisa bibliográfica.

\section{RETROSPECTIVA HISTÓRICA DA PRÁtICA DE LEITURA NO CONTEXTO ESCOLAR}

Até meados do século XIX, poucas eram as escolas que existiam no Brasil. No período Colonial, as práticas de ensino inicial eram ministradas nas próprias fazendas ou engenhos por uma pessoa letrada, geralmente, o padre ou por um mestre contratado para este fim. Poucas eram também as pessoas que podiam frequentar a escola. Nesse período, grande parcela da população era excluída de vários aspectos da vida social. Os escravos, por exemplo, eram proibidos de estudar e às meninas, entediase que era necessário oferecer apenas uma educação geral que lhes permitissem cumprir bem as tarefas domésticas, pois, as mulheres nessa época, tinham poucos direitos e eram educadas apenas para se casarem, terem filhos e cuidar da casa (MAIA, 2007).

Os livros didáticos por sua vez, praticamente não existiam em nossas escolas nesse período da história. Várias fontes, como romances, crônicas, autobiografias, relatos de viajantes e outras, indicam que o ensino e a prática de leitura nas escolas eram baseados em textos manuscritos como cartas, documentos de cartório, Bíblia e até mesmo na Constituição do Império e no Código Criminal. A leitura neste período da 
nossa história assumia apenas o papel de instruir as pessoas para a vida em sociedade (BARBOSA, 1994).

A partir do Período Imperial, a sociedade se tornou mais complexa e algumas iniciativas foram sendo tomadas no sentido de se ampliar a oferta de escolarização para a população. Novos cargos de trabalho foram surgindo, novos costumes foram sendo incorporados. A instrução e a educação passaram a ser vistas como fundamentais para o desenvolvimento cultural e econômico do país, ou seja, um passaporte para o mundo civilizado (MAIA, 2007).

No Brasil, a impressão de livros se iniciou a partir de 1808, com a implantação da Imprensa Régia. No entanto, até mesmo na escola, os momentos de leitura continuavam sendo raros e não despertavam prazer no leitor. Ainda eram poucos os locais destinados à prática de leitura naquele período, havia poucas bibliotecas e livrarias e como consequência, poucos também eram os leitores.

Os momentos destinados a leitura na escola até então, não despertavam prazer no leitor, ao contrário, eram vistos como momentos de tédio, tortura e aborrecimento, servindo apenas para instruir e transmitir regras e modelos de comportamentos.

A literatura passa a ter então, papel fundamental na formação de leitores, despertando o prazer e o gosto pela leitura. E, apesar de pouco difundida na escola naquele período e de difícil acesso, a literatura acaba mostrando ao leitor outro universo cheio de alegria e aventuras, onde se podia viajar por locais jamais vistos e conversar com pessoas que nunca fora encontrada frente a frente. Isso era fascinante e acabou por despertar a atenção de algumas pessoas que posteriormente se tornaram grandes leitores e escritores de sucesso (BARBOSA, 1994).

A partir da segunda metade do século XIX, começaram a surgir no Brasil livros didáticos destinados especificamente às séries iniciais da escolarização. Embora, inicialmente, muitos desses livros tenham sido fabricados na Europa, o surgimento dos mesmos foi de suma importância para a educação, pois, foram considerados 
inovadores e serviram como propulsores para o surgimento de editoras e escritores em território nacional (MAIA, 2007).

Em 1868, Abílio César Borges, dono de escola e que era contra os castigos corporais adotados nas maiorias das escolas do país, iniciou a publicação de uma série livros destinados às séries iniciais da escolarização. Seus livros receberam muitos elogios pela crítica intelectual da época e foram considerados inovadores, substituindo as grosseiras cartilhas ou materiais manuscritos. Tinham caráter enciclopédico e traziam conteúdos de várias áreas do conhecimento, eram de cunho mais instrutivo do que moral. Os livros de Borges foram reeditados várias vezes e serviram de base para educar gerações de brasileiros. No entanto, apesar de serem considerados inovadores eles ainda não conseguiam despertar nos alunos a ânsia e o prazer pela leitura. Prazer este, que só era atingido pelo leitor ao entrar em contato com obras literárias fora da escola de acordo com o relato de Graciliano Ramos - um dos maiores escritores de Língua Portuguesa - em sua autobiografia (BARBOSA, 1994).

Ainda no século XIX, outras séries de livros foram publicadas, dentre elas, se destacaram a de Felisberto de Carvalho. Seus livros, assim como os de Borges, também traziam conteúdos de diversas áreas de conhecimento, porém, o foco era oferecer à criança, além da instrução, ensinamentos morais (MAIA, 2007).

Apesar de não ser essa a intenção da escola naquela época, em alguns casos, a leitura dos livros de Felisberto até provocava prazer. Nesses livros havia algumas ilustrações com cores e as lições vinham sempre acompanhadas de exercícios. Esses livros foram muito importantes para impulsionar a educação brasileira e foram muito usados em nossas escolas até meados do nosso século (BARBOSA, 1994).

Já no final do século passado e início deste, houve a expansão da escolarização. Em 1899, instalou-se o governo republicano que adotou como uma de suas metas as reformas no ensino. Novos métodos e teorias educacionais passaram a ser difundidos nesse período e várias reformas começaram a ser propostas. Porém, apesar das mudanças significativas que houve no contexto escolar nessa época, muitas escolas, continuaram semelhantes às das gerações anteriores. Os castigos físicos como a 
palmatória permaneceram presentes no ambiente escolar, os prédios continuaram sendo inadequados para uma escola, pois, tinham salas mal iluminadas, mobiliários precários e professores mal remunerados. As escolas desse período agrupavam os alunos por nível de instrução e não por série como ocorre atualmente. Os professores não davam aulas como hoje, eles "tomavam" a lição enquanto os demais alunos permaneciam obedientemente em suas carteiras lendo a lição do dia (MAIA, 2007).

A partir de então, surgiram também no país às primeiras grandes editoras. Os autores passaram a publicar seus livros aqui mesmo no Brasil, nasce então à literatura brasileira. Os livros estrangeiros continuaram a serem importados, pois, ainda eram um auxílio importante. Os jornais também passaram a publicar, sistematicamente, histórias através de folhetins, possibilitando, o aumento gradativo do público leitor.

No início do século XX, dois autores se destacaram. Olavo Bilac e Manuel Bonfim publicaram o livro de leitura: Através do Brasil, que ao mesmo tempo em que prendia a atenção do leitor servia de subsídio para o professor em sua ação docente, pois dispunha de material para desenvolver os diversos assuntos necessários à instrução das crianças. Em 1921, surge outro livro que marcaria a história dos livros de leitura: Narizinho Arrebitado de Monteiro Lobato. Este livro se diferenciava de toda a literatura didática produzida naquela época no Brasil e trouxe para a escola um aspecto até então ignorado: o prazer pela leitura. O livro de Monteiro Lobato se tornou um dos maiores sucessos da literatura infantil brasileira (BARBOSA, 1994).

As reformas ocorridas no ensino entre as décadas de 20 e 50 possibilitaram a expansão da escola pública, dando acesso à educação a uma grande maioria da população, uma vez que, nessa época mais de $80 \%$ da população era analfabeta.

Entre as décadas de 1950 e 1970 outros métodos educacionais foram surgindo e o ensino passou a ser centrado no aluno e nas suas necessidades. O ensino público se expandia cada vez mais e aumentava, significativamente, cada vez mais o número de pessoas ingressas na escola. Nesse período, os acessos aos meios de leitura aumentaram bastante nas grandes cidades. $O$ número de livrarias cresceu e foram criadas também as bibliotecas populares e ambulantes (MAIA, 2007). 
A partir da década de 70 , muitos outros livros de leitura surgiram. Na escola, os livros passaram a ter um tempo menor de utilização devido à necessidade de atualização dos conteúdos que se tornam cada vez mais complexo na medida em que as pesquisas sobre os conhecimentos pedagógicos avançam.

Nesta mesma década a literatura infantil passa então, a fazer parte das atividades de leitura na escola propiciando momentos de prazer ao ato de ler e atraindo cada vez mais novos leitores. Os novos livros - literários e didáticos - dão liberdade de escolha ao leitor e subsidiam cada vez mais a ação pedagógica trazendo consigo mais instruções aos professores (BARBOSA, 1994).

Constata-se então, que durante muito tempo a leitura foi utilizada na escola apenas como suporte para as aulas de gramática e como algo que só podia ser adquirido pela memorização e não era trabalhada no sentido de formar leitores intelectualmente autônomos, conscientes e críticos da realidade a sua frente. Os alunos de tempos anteriores à década de 70, não tinham liberdade de escolher os livros que realmente gostariam de ler (MAIA, 2007).

Felizmente, no decorrer dos anos, muitas mudanças ocorreram, ampliaram-se às oportunidades de leituras e novos recursos foram inventados para facilitar o ato de ler. Outras fontes de leitura como jornais, revistas, rótulos, e outros foram incorporados às salas de aulas. A revolução tecnológica também veio modificando e revolucionando o ensino nas escolas primárias. Com os novos recursos disponíveis, surgem também outras modificações: a forma pela qual a criança aprende a ler e escrever

\subsection{O APRENDER A LER}

Por muito tempo imaginou-se que a criança só aprenderia a ler se estivesse inserida na escola. Por conta disso, foram criadas as cartilhas de alfabetização e outros meios didáticos com regras sistemáticas do passo a passo que se deveria seguir para alfabetizar uma criança. Hoje sabemos que isso não é necessariamente verdade, pois, sabe-se que o processo de aprendizagem transcende os espaços escolares e que não existem receitas prontas para inserir uma criança no mundo da leitura. 
"Ler não significa a repetição infindável das atividades escolares, a decodificação das letras ou dos símbolos" (BRASIL, PCN's, 1997, p. 57). Ler é uma atividade extremamente rica e complexa, que envolve não só os conhecimentos fonéticos ou semânticos, mas também culturais e ideológicos. Pode ser um processo de descoberta, uma tarefa desafiadora ou mesmo lúdica. É uma atividade de interação que obedece a objetivos e necessidades socialmente determinados onde pode-se compreender e interpretar o mundo que o cerca em todas as suas formas.

Geraldi (1996, p. 28) também entende a leitura como prática social e afirma que:

Aprender a ler é, assim, ampliar as possibilidades de interlocução com as pessoas que jamais encontraremos frente a frente e, por interagirmos com elas, seremos capazes de compreender, criticar e avaliar seus modos de compreender o mundo, as coisas, as gentes e suas relações. Isto é ler.

Para Solé (1998, p. 22) "a leitura é um processo de interação entre leitor e o texto, onde se tenta satisfazer (obter uma informação pertinente para) os objetivos que guiam a leitura".

A criança aprende ler muito antes mesmo de entrar na escola. Esse processo de aprendizagem se dá na interação com a família ou até mesmo fora dela, nos ambientes que frequenta.

Aprendemos ler nas formas mais simples da vida. Desde pequenos, quando conseguimos interpretar ou descrever as imagens, os desenhos ou figuras que aparecem num livro, revista, jornal, placa, quadro, televisão, computador ou paisagem à nossa volta, estamos lendo. É uma leitura diferente baseada nos conhecimentos que temos sobre algo e onde construímos um repertório de textos que são usados pela sociedade.

Martins (1994, p. 27) ao ampliar a noção de leitura afirma que "ler deve ser considerado um processo de apreensão de símbolos expressos através de qualquer linguagem, portanto, o ato de ler se refere tanto a algo escrito quanto a outros tipos de expressão do fazer humano" 
A leitura não deve ser entendida apenas como a decodificação de símbolos ou letras, e sim como um processo de compreensão que se dá pela interação entre a criança e o meio onde ela vive, ou seja, devemos entender que ler é a forma como a criança interpreta ou compreende um conjunto de informações.

De acordo com os PCN's:

É preciso superar algumas concepções sobre o aprendizado inicial da leitura. A principal delas é a de que ler é simplesmente decodificar, converter letras em sons, sendo a compreensão consequência natural dessa ação. Por conta desta concepção equivocada a escola vem produzindo grande quantidade de "leitores" capazes de decodificar qualquer texto, mas com enormes dificuldades para compreender o que tentam ler. (BRASIL, 1997 p. 55).

Para auxiliar no processo de aprendizagem da leitura é preciso se compreender as fases do desenvolvimento da criança e oferecer a ela, desde cedo, um ambiente rico em livros, jogos educativos e outros materiais que irão despertar o gosto pela leitura, o desejo de investigar, de descrever e compreender o que está a sua volta.

Freire (2005 apud Maia 2007, p. 27) nos diz que: "aprender a ler o mundo, compreender o seu contexto, não é uma manipulação mecânica de palavras, mas uma relação dinâmica que vincula linguagem e realidade".

Em casa ou na escola, quando contamos ou lemos uma história para uma criança e mostramos a ela as gravuras existentes no texto, ela está se alfabetizando, independentemente da idade. E, posteriormente ao entrar em contato novamente com aquela história, mesmo que não saiba ler ainda, a criança será capaz de fazer sozinha sua própria releitura, usando palavras que são próprias do seu cotidiano, mas sem perder a verdadeira essência da história.

Ainda de acordo com Freire (1984 apud Maia 2007, p. 27) "o ato de ler não se esgota na decodificação pura da palavra escrita, mas se antecipa e se alonga na inteligência do mundo". 
A leitura se desenvolve na convivência com próprio mundo. Um indivíduo aprende ler quando relaciona o que lê com o seu conhecimento de mundo, ou seja, com as experiências que traz em sua "bagagem". Assim, cada pessoa terá uma leitura particular de um mesmo texto, dependendo do seu conhecimento prévio. Esse conhecimento antecipado que se tem de algo é fundamental para a construção dos significados acerca do lido.

\subsection{A LEITURA NO CONTEXTO ESCOLAR}

A leitura é uma das principais atividades da instituição escolar e precisa ser trabalhada com dedicação, pois, a aquisição da mesma é a base para o desenvolvimento cognitivo do aluno e para o sucesso do processo de ensino e aprendizagem.

Uma das prioridades da escola é oportunizar aos alunos o aprendizado da leitura e da escrita, valorizando-as igualmente, pois ambas estão interligadas. Logo, deve propiciar todos os instrumentos e condições para que a criança tenha um contato positivo com os livros, colocando à sua disposição materiais de leitura de diversas fontes. Entretanto, na maioria das escolas estes materiais ficam engavetados em armários, sendo usados apenas esporadicamente. Barbosa (1994, p. 141) afirma que "a escola deve se organizar em função de um novo conceito de leitura, que supõe a adoção de um novo processo de aprendizagem".

De acordo com Solé (1998, p. 32), "um dos múltiplos desafios a serem enfrentados pela escola é o de fazer com que os alunos aprendam a ler corretamente [...]". A função da escola não é só de ensinar a ler mecanicamente, mas ensinar ler criticamente, a interpretar os diferentes tipos de leitura, para evitar a reprodução das desigualdades sociais, conhecendo-as e buscando superá-las através da aquisição da leitura e da escrita, e assim tornar a sociedade mais igualitária.

Ensinar a ler não é tarefa fácil. Ao contrário, é uma atividade complexa que exige muito esforço, paciência e determinação de ambas as partes envolvidas neste processo. $\mathrm{E}$ como, na maioria dos casos, a criança vem de casa sem nenhum contato anterior com o mundo da leitura, é a escola quem arca com essa imensa responsabilidade. Silva 
(1987 apud Maia 2007, p. 28), um dos pioneiros no uso da terminologia "pedagogia da leitura", afirma: "Ler é, em última instância, não só uma ponte para a tomada de consciência, mas também um modo de existir no qual o indivíduo compreende e interpreta a expressão registrada pela escrita e passa a compreender-se no mundo".

Não basta saber decifrar os códigos escritos. Para ser um bom leitor é preciso conseguir resolver tarefas simples do cotidiano escolar como interpretar textos, saber o significado de uma palavra ou entender o sentido de uma frase. Para isso, é necessário se apreender a mensagem transmitida pelo conjunto de palavras que formam frases e textos.

Silva (1986 apud Maia 2007, p. 28), faz uso de palavras fortes como "conscientização, liberdade, cidadania, e transformação" e concebe a leitura como "um instrumento para o processo de reconstrução da sociedade brasileira", ao mesmo tempo em que denuncia a falta de uma política de direito à leitura: "na sociedade brasileira, constituída de classes com intenções antagônicas, a leitura se apresenta como uma questão de privilégio e não de direito de toda a população".

Infelizmente, a escola foi e continua sendo excludente, hoje um pouco mais mascarada, mas continua sendo excludente quando privilegia as classes sociais mais elevadas em detrimento das mais pobres.

\section{FATORES QUE ESTIMULAM O PROCESSO DE LEITURA}

A leitura é um processo contínuo que depende de várias metodologias e estratégias, as quais devem estar de acordo com a idade ou estágio cognitivo do aluno. A criança deve ser exposta desde cedo a um ambiente alfabetizador repleto de livros e materiais escritos ou digitados, mídias eletrônicas e outros, seja em casa ou na escola.

São muitos os gestos de leitura que podem influenciar as crianças como a simples prática de ler um texto ou uma história em voz alta junto a uma criança. Muitos também são os tipos de textos que circulam nas instituições de ensino e nos grupos sociais. 
Para estimular o processo de desenvolvimento da leitura a escola deve antes de tudo propiciar um ambiente acolhedor, harmonioso e rico em livros de diferentes gêneros textuais, jogos educativos e outros recursos como mídias eletrônicas que costumam prender a atenção do aluno.

Os PCN's (1997, p. 36), registram que: "Não se formam bons leitores oferecendo materiais empobrecidos, justamente quando as crianças são iniciadas no mundo da escrita". As pessoas aprendem a gostar de ler quando, de alguma forma a qualidade de suas vidas melhora com a leitura.

A escolha correta do material a ser utilizado nas salas de aula será de suma importância e decisivas para atrair a atenção das crianças, principalmente, nas séries iniciais. No entanto, vale ressaltar também que é de fundamental importância que o docente tenha domínio do recurso utilizado em seu trabalho para possibilitar a construção e o desenvolvimento de habilidades nos educandos.

Textos literários, revistas em quadrinhos, jornais, textos em mídias eletrônicas, brincadeiras e jogos educativos são a base para envolver os alunos e se fazer da aula um momento de aprendizado e descontração. A escola precisa disponibilizar-se de materiais como estes e os docentes devem ousar na sua criatividade durante as aulas.

De acordo com os PCN's:

Para aprender a ler, portanto, é preciso interagir com a diversidade de textos, testemunhar a utilização que os leitores fazem deles e participar de atos de leitura de fato; é preciso negociar o conhecimento que já se tem e o que é apresentado pelo texto, o que está atrás e diante dos olhos, recebendo incentivo e ajuda de leitores experientes. (BRASIL, 1997, p. 56).

Os PCN's (BRASIL, 1998, p. 149), confirmam ainda que: "o envolvimento do aluno no processo de aprendizagem deve propiciar ao aluno encontrar sentido e funcionalidade naquilo que constitui o foco dos estudos em cada situação de sala de aula".

É fundamental entender que para formar leitores, se faz necessário à escola criar ambiente estimulador, com condições favoráveis para que se desenvolva a prática da 
leitura, onde $\mathrm{o}$ aluno se sensibilize pela necessidade de ler, criando um espaço agradável no qual o leitor queira permanecer e poder desfrutar o que há de melhor, tornando assim um veículo facilitador da aprendizagem no qual lhe dará autonomia diante do seu conhecimento.

Segundo os PCN's (1998, p. 58), para que as dificuldades da leitura sejam superadas e os alunos se sintam estimulados, a escola deve:

Dispor de uma boa biblioteca, [...] de um acervo de classe com livros e outros materiais de leitura; organizar momentos de leitura livre em que o professor também leia. Para que os alunos não acostumados com a participação em atos de leitura e que não conhecem o valor que ela possui, possam ver seu professor envolvido com a leitura se sintam seduzidos e seja despertado pelo desejo de ler também.

A escola precisa oferecer condições para os alunos construírem sua própria aprendizagem na leitura, além de conquistar o educando de forma prazerosa, para que ele desenvolva o hábito de ler, dispondo atenção não só para os alunos bemsucedidos, mas também para aqueles com dificuldades de leitura, possibilitando a todos os alunos a chance de se tornarem bons leitores.

\subsection{SUGESTÕES PEDAGÓGICAS E FORMAS DE INTERVENÇÕES} FAMILIARES NO CONTEXTO DA LEITURA

Para incentivar as crianças e fazer da leitura uma prática prazerosa, pode-se seguir algumas maneiras simples que ajudarão muito na aquisição do conhecimento e que podem ser praticadas tanto na escola pelos docentes como em casa pelos pais e familiares envolvidos no processo de aprendizagem da criança. Segundo Cramer; Castle (2001), São elas:

Ler em voz alta diariamente para a criança, independentemente de sua idade, pois, aos poucos ela vai se familiarizando com a leitura e se acostumando a ver e tocar nos livros.

Inicialmente use livros ilustrados sem textos ou com poucas palavras, eles podem ajudar no desenvolvimento da percepção visual, da imaginação e na leitura das 
imagens. Auxilie a criança apontando as cores e dizendo o nome das coisas. Livros simples podem ensinar para a criança que há espaços entre as palavras e que a escrita vai da esquerda para a direita o que mais tarde irão ajudá-la no desenvolvimento da leitura.

Contar histórias para as crianças estimulando-as a fazer perguntas, a falar sobre a história que acabou de ouvir, a tentar adivinhar o que vai acontecer com as personagens de acordo com o desenrolar da trama. Leve-o a relacionar os fatos ou coisas da história com o seu dia a dia.

Tentar desenvolver em parceria com pais e escola programas de incentivo ao desenvolvimento da leitura. Buscar parcerias na comunidade e desenvolver programas de leitura para voluntários, pais e crianças, assim, pode-se desenvolver de forma prazerosa a leitura de ambas as partes.

O dicionário ilustrado (infantil) é uma ferramenta estimulante, pois, prende a atenção das crianças e desenvolve o hábito de ler brincando. Provoque-as a descobrir o significado das palavras.

Expor materiais de escrita como giz de cera, coleção, lápis com borracha, canetas, papeis entre outros ao alcance das crianças para que elas se sintam confiantes e livres para se expressarem.

Assistir e incentivar a assistir programas educativos na TV, vídeo ou computador. Esses programas além de divertidos ensinam coisas interessantes como conteúdos escolares ou coisas que podem ser usadas no dia a dia das pessoas.

Manter o Hábito de visitar uma biblioteca ou livraria com frequência, levar a criança a esses ambientes desde pequeno, começar com visitas semanais e depois vai ampliando a assiduidade dessas visitas. Incentivar a escolher os livros que mais the agrada, pegando-os emprestado ou comprando-os.

Ler com frequência, as atitudes servirão de exemplo para as crianças em casa ou na escola. 
Com atitudes simples pode-se fazer muito para ajudar no desenvolvimento intelectual e educacional das crianças. Essa curiosidade vai determinar o futuro das crianças como leitoras. É importante lembrar que o gosto pela leitura deve começar antes da alfabetização, em casa, quando a criança fica fascinada pelo conteúdo dos livros que os pais leem para elas e aprimorada na escola no decorrer de sua vida escolar.

\section{CONSIDERAÇÕES FINAIS}

Neste trabalho forma feitas análises sobre a história do ensino da leitura em nossas escolas, buscando refletir sobre as maneiras que a escola ensina e as maneiras que a criança aprende a ler. Percebe-se que são muitos os fatores que levam às dificuldades de leitura e a importância que escola, docentes e famílias têm juntas na aquisição das competências leitoras. Observou-se que anteriormente no início da colonização do Brasil muitos eram os entraves no ensino da leitura, pois, não eram todas as pessoas que tinham acesso à escola, não haviam métodos eficientes de ensino, não haviam livros atrativos para leitura ao alcance de todos e não era do desejo das classes sociais dominantes que as parcelas menos favorecidas da população se tornassem pessoas intelectualmente independentes.

No entanto, observou-se também que ao longo dos anos houve avanços significativos no contexto escolar, uma vez que, as necessidades foram surgindo e a escola se expandiu, com isso as pessoas se tornaram mais exigentes, novos estudos surgiram e os métodos de ensino evoluíram, aumentaram-se o número de livros de leitura disponíveis a todos, dentre outras.

Porém, percebe-se que ainda há muito a se fazer no âmbito do ensino da leitura nas escolas. Como perspectivas para o futuro, espera-se que escolas, docentes e famílias trabalhem juntas, adquirindo e aperfeiçoando a cada dia os hábitos saudáveis de leitura, seja em casa ou na escola, para que as futuras gerações não sofram tanto com as dificuldades de leitura que na atualidade assolam nossas escolas. 
Portanto, este trabalho de pesquisa serviu para perceber que é preciso refletir sobre o passado do ensino nas séries iniciais para se ter uma noção clara das causas dos problemas existentes nas escolas no presente.

\section{REFERÊNCIAS}

BARBOSA, José Juvêncio. Alfabetização e leitura. São Paulo: Cortez, 1994.

BRASIL, PCN's. Parâmetros Curriculares Nacionais - Língua Portuguesa. Brasília, 1997.

BRASIL. Secretaria de Educação Fundamental. Parâmetros curriculares nacionais: terceiro e quarto ciclos do ensino fundamental: introdução aos parâmetros curriculares nacionais / Secretaria de Educação Fundamental. - Brasília: MEC/SEF, 1998.

CRAMER, Eugene H.; CASTLE, Marrietta (orgs.). Incentivando o amor pela leitura. Porto Alegre: Artmed, 2001

FREIRE, Paulo (1977) A mensagem de Paulo Freire Teoria e prática da libertação, Porto: Nova Crítica

GERALDI, João Wanderley. Linguagem e ensino: exercícios de militância e divulgação. Campinas: ALB; Mercado de Letras, 1996.

KLEIMAN, Angela. A literatura na formação de leitores e professores. Editora Paulinas. São Paulo, 1993.

MAIA, Joseane. A literatura na formação de leitores e professores. Editora Paulinas. São Paulo, 2007.

MARTINS, Maria Helena. O que é Leitura. 19 ed. São Paulo: princípios, 1994

SILVA, Ezequiel Theodoro da. Concepções de leitura e suas consequências no ensino. Perspectiva. Florianópolis, v.17, n. 31, p. 11 - 19, jan.jun. 1986. 
SOLÉ, Isabel. Estratégias de Leitura. 6를. ed., Porto Alegre: Artmed, 1998.

Enviado: Agosto, 2019.

Aprovado: Novembro, 2019. 